\title{
A EDUCAÇÃO AMBIENTAL ESTÉTICA E AS RELAÇOES DE PERTENCIMENTO NO PROCESSO DE AMBIENTALIZAÇÃO CURRICULAR
}

\author{
AESTHETIC ENVIRONMENTAL EDUCATION AND THE RELATIONS OF \\ BELONGING IN THE PROCESS OF CURRICULAR ENVIRONMENTALISATION \\ LA EDUCACIÓN AMBIENTAL ESTÉTICA Y LAS RELACIONES DE PERTENENCIA
EN EL PROCESO DE AMBIENTALIZACIÓN CURRICULAR
}

Junior Cesar Mota juniormota@furg.br

Cláudia da Silva Cousin profaclaudiacousin@gmail.com Dione Iara Silveira Kitzmann docdione@furg.br

REVISTA PEDAGÓGICA

Revista do Programa de Pós-graduação em Educação da Unochapecó | ISSN 1984-1566 Universidade Comunitária da Região de Chapecó | Chapecó-SC, Brasil Como referenciar este artigo: MOTTA, J.C.; COUSIN, C. S.; KITZMANN, D. I. S. A educação ambiental estética e as relações de pertencimento no processo de ambientalização curricular. Revista Pedagógica, Chapecó, v. 20, n. 45, p. 207-226, set./dez. DOI: http://dx.doi.org/10.22196/rp.v20i45.3986

RESUMO: A ambientalização curricular (AC) se tornou um assunto importante para refletir sobre as situações envolvendo a esfera socioambiental vivenciadas cotidianamente. Esses problemas se agravam à medida que o sentimento de pertencimento aos lugares se enfraquece. Pautados nessas questões e refletindo sobre o papel da educação ambiental para a (re)apropriação desse sentido de pertença, este ensaio, emergente do trabalho final da disciplina "A relação de pertencimento na constituição dos educadores ambientais" do Programa de Pós-Graduação em Educação Ambiental da Universidade Federal do Rio Grande (FURG) e, por isso, se propõe discutir acerca da Educação Ambiental Estética como uma possível ferramenta ao fortalecimento das relações de pertencimento na ambientalização curricular. Pressupõe-se que sem este fortalecimento não há uma efetiva participação dos sujeitos na implementação do processo de ambientalização, que passa a ser visto fragmentado e sem a devida importância para as instituições de ensino superior

Palavras-chave: Ambientalização curricular. Educação superior. Educação ambiental. Estética. Pertencimento.

\footnotetext{
ABSTRACT: The curricular environmentalization has become an important subject to think about the worrying situations involving the socio-environmental sphere experienced on a daily basis. These problems worsen as the sense of belonging to places weakens. Based on these questions and reflections on the role of environmental education for a (re)appropriation of the sense of belonging to places, this essay, emerging of the final work of the discipline "The relation of belonging in the constitution of environmental educators" of the Postgraduate Environmental Education Program at Rio Grande Federal
}

University (FURG), and for this reason, it proposes to discuss about the aesthetic environmental education as a possible tool for strengthening the relations of belonging in the process of curricular environmentalization. It is assumed that without this strengthening there is no effective participation of the subjects in the implementation of the environmentalization process, which is seen as fragmented and unimportant for higher education institutions

Keywords: Curricular environmentalization. Higher education. Aesthetic enviromental education. Belonging.

RESUMEN: La ambientalización curricular se ha convertido en un tema importante para reflexionar sobre situaciones que involucran la esfera socioambiental experimentada diariamente.Estos problemas empeoran a medida que la sensación de pertenencia a los lugares se debilita.Guiados sobre estos temas y reflexionando sobre el papel de la educación ambiental para la (re) apropiación de este sentido de pertenencia, este ensayo, emergiendo de las reflexiones establecidas en la disciplina "La relación de pertenencia en la constitución de educadores ambientales" del programa de Postgrado en Educación Ambiental en la Universidade Federal do Rio Grande (FURG) y, por eso, propone discutir la educación ambiental estética como una herramienta posible para fortalecer las relaciones de pertenencia en el entorno curricular.Se supone que sin este fortalecimiento no existe una implicación efectiva de los sujetos en la implementación del proceso de ecologismo, que se está viendo fragmentado y sin la debida importancia para las instituciones de enseñanza superior.

Palabras-clave: Ambientalización curricular. Educación superior. Educación ambiental estética. Pertenencia. 


\section{INTRODUÇÃO}

Em meio a uma brutalidade maciça e dominadora imposta pelo sujeito homem sobre a natureza, é indispensável que o ser humano consiga (re)estabelecer um sentido de pertencimento ao lugar em que vive para que haja uma quebra de paradigma socioambiental dominante. Souza Santos (2006), ao discutir sobre a crise do paradigma da ciência moderna, nos mostra que esta negava a racionalidade de outras formas de conhecimento, tal como o conhecimento do senso comum e das humanidades que se desenvolve no lugar a partir das narrativas existenciais. Ainda, o autor discute a emergência de outro paradigma, que considera que todo conhecimento científico-natural é científico-social; todo conhecimento é local e total e todo conhecimento é autoconhecimento.

Seria ceticismo negar que as catástrofes planetárias estão cada vez mais eminentes, tanto na esfera local quanto na global. Sejam elas causadas por ações antrópicas ou por causas naturais, o fato é que não há um sistema de escape ou soluções imediatas para contornar a situação. Vive-se em uma crise civilizatória sem precedentes e, muitas vezes, esta é camuflada pelo sistema vigente que insiste em banalizar e mascarar os acontecimentos, agravando, assim, a crise socioambiental.

Nestas circunstancialidades dessa mundanidade (SANTOS, 2008) contemporânea, os sujeitos se tornaram incapazes de se autoafirmar enquanto indivíduos com uma identidade própria, marcada pelas suas vivências e experiências. Enquanto sujeitos com uma autoafirmação identitária líquida (BAUMAN, 2003) que buscam no coletivo uma razão para sua corporeidade, existe uma busca por uma (re)acomodação da existência subjetiva em lugares guardadores de memórias, capazes de fortalecer a essência e a identidade de cada um. Giddens (2002) caracterizava esses lugares de fuga e de proteção como casulos protetores, pois, segundo ele, são capazes de proporcionar segurança, refúgio e aconchego em uma situação de desencaixe social, além de garantir a condição protetora do mundo circundante (SANTOS, 2008). Para Giddens (2002), o desencaixe se refere às esferas que compõem a circunstancialidade do cotidiano.

Entretanto, Bauman (2003) aponta que, em tempos

1 A modernidade líquida, segundo Bauman (2003), pode ser conceituada devido à fluidez das relações, dos modos de vida, das crenças, culturas e valores que se tornam mutáveis a partir de pressões sociais impostas. Logo, na contemporaneidade, as vidas humanas passam a ser objetos de consumo, vazias e muitas vezes sem um sentido existencial. É como se fossem recipientes vazios à espera de serem preenchidos por padrões já definidos. de modernidade líquida ${ }^{1}$, esses lugares se apresentam cada vez mais fragilizados e estão desaparecendo, pelo fato de estarem encharcados de conflitos, disputas, inseguranças, que constrangem, abalam, angustiam e cerceiam a liberdade da sociedade. Esta angústia é internalizada em consequência desses fatores sociais extrínsecos que estão no mundo vivido e que muitas vezes, (se não na maioria), tornam os sujeitos passivos e acríticos, face à perda de identidade dos lugares.

Perante o exposto, percebe-se a urgente necessidade de que questões como estas sejam discutidas nos processos 
de formação nas instituições de ensino superior (IES). Isto porque é preciso que ocorram transformações nas formas de ser-e-estar no mundo (HEIDEGGER, 2015) dos futuros profissionais em formação, dos gestores públicos e da sociedade civil, ante a complexidade das interações do ser humano. Afinal, nunca é demais lembrar que a universidade precisa, em todas as suas áreas, "[...] recuperar sua capacidade reflexiva sobre os grandes eixos da cultura atual, seja do ponto de vista científico/tecnológico, seja do ponto de vista humanístico/cultural. Em vez de se submeter ao sistema, deve submeter o sistema ao debate" (GOERGEN, 2000, p. 156).

Corroborando a ideia de que há uma necessidade emergente de se discutir e debater acerca do sistema vigente, autores como Figueiredo et al. (2014), Marcomin e Silva (2010), Morales (2009), Guimarães et al. (2009), Sato e Santos (2003), entre outros, consideram ser indiscutível o papel das IES na integração das dimensões da temática socioambiental. Essa integração pode ocorrer em suas diversas frentes de atuação, tais como no ensino, na pesquisa, extensão e gestão, em prol de uma construção de uma sociedade mais justa, menos desigual e ética.

Isto nos remete a pensar a universidade como um lugar capaz de permitir a formação de concepções inovadoras, reflexivas e solidárias. Ao formar profissionais com essas capacidades se fortalece um ciclo formativo para além da academia, pois essas competências ambientalmente sustentáveis se refletem na formação de outros sujeitos, a partir desses agentes que internalizam as questões socioambientais com base no currículo do curso acadêmico. Destarte, as IES, de acordo com Guerra et al. (2015, p. 127), "[...] assumem importante papel na responsabilidade socioambiental, de modo que a temática da ambientalização passa a se constituir em uma nova linha de investigação e intervenção, em que a EA assume seu papel transformador e emancipatório [...]”.

O processo de ambientalização pode ser compreendido como a integração da temática socioambiental de forma articulada, em todos os níveis e modalidades, do processo educativo, em caráter formal e não-formal, como prevê a Política Nacional de Educação Ambiental em seu Art. $2^{\circ}$. Deste processo faz parte a ambientalização institucional, podendo ser chamada de sistêmica, e a ambientalização curricular. A primeira, segundo Kitzmann e Mota (2017), é um processo globalizante, envolvendo as dimensões da pesquisa, da extensão, do ensino e da gestão. Já a segunda remete à integração de "[...] conhecimentos, de critérios e de valores sociais, éticos, estéticos e ambientais nos estudos e currículos universitários, no sentido de educar para a sustentabilidade [...]" (GUERRA, FIGUEIREDO, 2014, p. 111), voltando-se mais ao eixo do ensino.

O caráter transformador e emancipatório da educação ambiental (EA) mencionado anteriormente, quando integrado nos currículos que orientam as práticas 
2 As Rodas de Formação, segundo Warschauer (2001) não se referem à estrutura apenas, mas à qualidade da interação, às partilhas que elas facilitam. Haver espaços e tempos definidos para o encontro das pessoas em círculos não é suficiente (e talvez nem estritamente necessário), apesar desta forma ser facilitadora, mas é a qualidade das trocas estabelecidas no processo partilhado que propicia o desenvolvimento criativo individual e grupal: o cuidado mútuo, a escuta sensível, o acolher e ser acolhido, a paixão por aprender e ensinar, de ensinar e aprender, a paciência no falar e ouvir, a amorosidade na convivência, a tolerância nas diferenças, o prazer estético partilhado, o respeito durante os conflitos, a coragem de ver-se no outro, de olhar para ele e para si, o formar-se formando. teórico-metodológicas e as demais vivências nas instituições de ensino, permite que contribuam para a mudança de um paradigma que ainda é conservador, positivista e fragmentado, imposto pela ciência moderna na construção dos conhecimentos. Por ainda persistir esse modelo curricular, o processo de ambientalização parece ser barrado por obstáculos epistemológicos que não permitem um repensar das ações institucionalizadas nesses lugares de aprendizagens e, como consequência disto, o currículo ambientalizado pode, muitas vezes, ser visto como um horizonte utópico a ser alcançado.

Dessa forma, para que o processo de ambientalização curricular (AC) ocorra, é necessário que os sujeitos que estão neste lugar a ser ambientalizado o compreendam como um lugar de pertencimento, tornando as ações a serem desenvolvidas significativas e coerentes com os discursos acerca das temáticas socioambientais e curriculares. Embora, talvez, esse sentido de pertencimento ao lugar não se demonstre (não significando que não exista), a educação ambiental estética (EAE) pode contribuir para que este se potencialize, pois está estreitamente "[...] conectada com os sentidos e os valores do ser-humano, oriundos dos experimentos sensoriais e significativos baseados em concepções individuais e coletivas, vivenciadas e construídas durante a história de vida de cada um." (MOTA, 2016, p. 3).

Assim sendo, este ensaio busca refletir, compreender e evidenciar a importância da EAE e do pertencimento ao lugar, no fortalecimento das relações de AC. Para auxiliar neste processo de compreensão, algumas questões foram desenvolvidas para mediar o processo de discussão, tais como: Que fazer para resgatar a identidade dos sujeitos e dos lugares fragilizados pelo sistema econômico capitalista? Como firmar a essência, a existência e a corporeidade dos indivíduos em lugares que estão tendo sua história e identidade sobrepujadas pelos vetores da economia, por conta dessa liquidez globalizante que insiste em banalizar situações precárias da existência humana no espaço e no tempo? Como (re)estabelecer as relações de pertencimento, e quais suas influências no processo de AC?

Ressalta-se que este ensaio teórico emergiu das reflexões tecidas na disciplina "A relação de pertencimento na constituição dos educadores ambientais”, do Programa de Pós-Graduação em Educação Ambiental da FURG, com a intenção de articular a questão de pesquisa da tese doutoral recentemente qualificada com as discussões realizadas na disciplina. As aulas da disciplina foram planejadas a partir do uso sistemático de Rodas de Formação ${ }^{2}$ (WARSCHAUER, 2001), devido a potencialidade formativa destas para o processo educativo. Nelas ocorreram a partilha de saberes, o diálogo, a escuta, a participação, a reflexão e a significação. Os encontros aconteceram semanalmente e foram elaborados registros reflexivos com o objetivo de significar as discussões tramadas nas Rodas de Formação com as pesquisas dos mestrandos e/ou doutorandos. Este 
texto emerge dos diálogos e das reflexões tramadas, tanto nas Rodas de Formação, a partir da partilha de saberes, quanto nos registros escritos em diálogo com a professora responsável pela disciplina.

Para uma melhor organização, seções foram desenvolvidas durante o lapidar das tessituras. Na primeira, encontra-se a Introdução, apontando os aspectos gerais do trabalho, bem como os objetivos e questões norteadoras para reflexão. A segunda, intitulada "A Educação Ambiental Estética e as relações de pertencimento ao lugar”, busca apresentar conceitos fundamentais para a compreensão desses temas e apontar como estes precisam estar interligados no processo de ressignificação de sentimentos, valores e ações. Na terceira seção, "O sentido de pertencimento e a Educação Ambiental Estética no processo de Ambientalização Curricular na Educação Superior”, são apresentados conceitos acerca da AC, bem como são discutidas as questões acerca das articulações necessárias entre a EAE e as relações de pertencimento para que o processo de AC possa emergir na prática.

\section{A EDUCAÇÃO AMBIENTAL ESTÉTICA E AS RELAÇÕES DE PERTENCIMENTO AO LUGAR}

Nesta seção, abordar-se-ão as discussões acerca da $\mathrm{EAE}$, dos lugares e do pertencimento. Para isto, aspectos relacionados ao espaço e aos lugares serão expostos, a fim de compreender como essas relações de pertencimento acontecem e como estas estão se fragilizando e vem se desconstruindo desde a invenção da ciência moderna, a qual fez com que os conceitos de lugar fossem obliterados e passassem a ser vistos como mera extensão, segundo Descartes ou, então, absolutos e vazios, como afirmava Newton. O lugar passou a ter o simples status de ser uma parte constituinte do espaço. Isto, fruto do dualismo sujeito-objeto e homem-natureza instaurado na modernidade (GRÜN, 2008). Esses dualismos fizeram com que emergisse um "[...] anestesiamento das capacidades sensíveis humanas, um afastamento acentuado da natureza e a concepção do mundo como uma construção exclusiva da ciência e da tecnologia” (DUARTE JR, 2010, p. 216). O lugar é um conceito geográfico importante e que é estudado pela Geografia desde que esta se tornou disciplina acadêmica, em 1870, por estar relacionado com as vivências cotidianas das pessoas em diálogo com aspectos econômicos, políticos, sociais e ambientais. Ao longo da história do pensamento geográfico, o conceito de lugar foi se tornando complexo, especialmente porque a geografia humanista, a partir do aporte teórico-metodológico da fenomenologia, nos permitiu compreender que o lugar é uma categoria de mediação da experiência humana no mundo: um guardador de relações corpóreas atreladas a um conjunto de circunstancialidades socioambientais que na contemporaneidade são especialmente produzidas pela materialidade espacial. 
Pautando nessas questões, antes de realizar quaisquer articulações entre EAE e pertencimento, se faz necessário conceituar os termos mencionados. Primeiramente, em relação à EA, convém ressaltar que ela

Não é [...] uma "forma" de educação (uma "educação para...”) entre inúmeras outras; não é simplesmente uma 'ferramenta' para a resolução de problemas ou de gestão do meio ambiente. Trata-se de uma dimensão essencial da educação fundamental que diz respeito a uma esfera de interações que está na base do desenvolvimento pessoal e social (SAUVÉ, 2005, p. 317).

Corroborand Sauvé, Tozoni-Reis (2006, p. 13), destaca que "[...] a educação ambiental é educação. Educação em suas várias dimensões: portanto, é preciso considerar a formação do homem no espaço educacional mais amplo ou no espaço educacional mais restrito [...]”. Desse modo, percebe-se que a EA está articulada aos processos de interação social, buscando promover uma abordagem crítica, reflexiva e construtiva acerca do "eu" como sujeito e como ser social envolvido com a realidade socioambiental dos problemas existentes e das possíveis soluções para minimizá-los e transformar a realidade em que está integrado, que é coletiva.

Para que este processo reflexivo de transformação da realidade aconteça, é necessário que os sujeitos estejam sensibilizados a isto. Para tal, a abordagem estética da EA emerge como potencializadora desse sentir sensível. Essa estética refere-se à "[...] capacidade do ser humano de sentir a si próprio e ao mundo de modo integrado" (DUARTE JR, 2010, p. 13), rompendo com o modelo fragmentado imposto pelo método cartesiano da sociedade moderna. Ainda,

A experiência estética funda novos valores. Ela abre perspectivas autônomas e pode levar o ser humano a se emancipar daqueles valores que, pela razão ou pela heteronomia de um imaginário social, são lhe incutidos como necessidades. Quem vivencia o fenômeno da experiência estética tem diante de si um mundo muito mais amplo e flexível que aquele desenhado pelas sociedades de consumo (MARIN; OLIVEIRA, 2005, p. 209).

Posto isto, convém mencionar que, na contemporaneidade, discutir a EAE como elemento basilar para se pensar numa possível (res)significação do mundo se torna indispensável, nos discursos e práticas. Pois, compreende-se que ela permite aos sujeitos uma capacidade de desenvolver uma percepção mais profunda sobre o lugar à sua volta, partindo da subjetividade de cada indivíduo, de suas representações sociais e das experiências sensíveis. Segundo Melo Filho (2006, p. 42) a percepção “[...] 
é influenciada pelas próprias características fisiológicas do ser humano, pelo seu caráter e personalidade e, também, por suas influências sociais e culturais."

Estabelecendo um diálogo com Merleau-Ponty (2006, p. 378), compreende-se que "[...] toda percepção supõe certo passado do sujeito que percebe, e a função abstrata da percepção, enquanto encontro de objetos, implica um ato mais secreto pelo qual elaboramos nosso ambiente”. Diante disto, nota-se que a percepção é própria da subjetividade do ser humano. Cada sujeito percebe os lugares de maneira diferenciada e o valor atribuído a determinada situação ou lugar está intrinsecamente interligado aos processos cognitivos e emocionais existentes no inconsciente de cada um. São os sujeitos que atribuem signos e símbolos aos lugares, a partir da experiência que é formada por um conjunto de circunstancialidades que dão corporeidade à sua existência e constroem sua identidade. Por isso, pode-se considerar que a identidade dos sujeitos se constitui na historicidade e na temporalidade do cosmo, a partir do ser-e-estar no mundo e do estar-com, abordados por Heidegger (2015), fundamentais para a construção do ser-aí.

Isso permite refletir sobre a relação da perda da identidade do lugar, que conduz a problemas identitários e de pertencimento. Para Grün (2008), essa perda e esses problemas são legados de uma modernidade que fez com que a sociedade passasse a ter o sentimento de viver em nenhum lugar. Viver em uma vasta escuridão de sentimentos e de caracterização de um corpo que não consegue ser mais sensível, estabelecer percepções profundas, passando a banalizar o que é fundante: a existência corpórea terrena. Essa perda da percepção profunda dos lugares e dos acontecimentos que ali se produzem afasta os sujeitos do (re)pensar e do (re) construir os elos afetivos e constitutivos da sua própria existência e de pertencimento ao lugar em que vive.

Para compreender a importância do pertencimento para o campo da EA é preciso alavancar uma discussão sobre o que é o lugar, pois como afirma Cousin (2010, p. 95), “[...] a compreensão do lugar é fundamental para a construção do sentimento de pertencimento, porque significa entender para além das suas condições naturais ou humanas o que acontece no espaço onde se vive”. Ou seja, o lugar é um potencial de afetividade formado por signos e símbolos que resultam de um conjunto de circunstâncias socioambientais que os indivíduos experienciam ao (com) partilhar o espaço-tempo existencial (COUSIN, 2010).

Entretanto, compreender e refletir sobre o sentido do lugar no mundo contemporâneo não se constitui em uma tarefa simples, haja vista uma vastidão de significados que podem ser atribuídos ao termo. Santos (2008), por exemplo, caracteriza o lugar como uma rede formada por uma contiguidade de pontos nodais resultante da intersecção da verticalidade (formadas por pontos mais distantes, interligados por processos sociais) e da horizontalidade (lugares próximos reunidos por uma continuidade territorial). 
Seguindo esta caracterização do lugar proposta por Santos (2008), o geógrafo Moreira (2006, p. 163) destacou que

[...] o lugar que a rede organiza em sua ação arrumadora do território é um agregado de segmentos ao mesmo tempo internos e externos de atividades. A contiguidade é o interno que integra os segmentos numa única unidade regional de espaço. É a horizontalidade. Por sua vez, a nodosidade é o externo que integra numa coalescência os segmentos contíguos ao fluxo do mundo verticalmente. É a verticalidade. Cada ponto local da superfície terrestre globalizado em rede vai ser o resultado desse encontro entrecruzado de horizontalidade e de verticalidade. E é isso o lugar.

Ainda para Santos (2008), cada lugar é objeto de uma razão local e de uma razão global, convivendo dialeticamente. Logo, compreender a dialética local/global, na contemporaneidade, é fundamental para pensar o lugar, visto que este é o palco da existência humana, pois é nele que a vida e a experiência se dão e, atualmente, o seu arranjo espacial está sendo modificado de forma intensa, mercê dos vetores da economia que se impõem.

Além do mais, o lugar pode ser definido sob três abordagens: como acontecimento, fazendo com que o sujeito sinta e atribua um significado ao lugar de acordo com suas percepções e valores acerca do acontecido; como estrutura, onde o lugar é o espaço físico como correspondente da construção do significado atribuído pelos sujeitos; e como acontecimento e estrutura, no qual o espaço físico influencia os acontecimentos. Entretanto, às vezes, o espaço como estrutura somente é percebido com maior criticidade quando o espaço físico não suporta uma ação imposta a ele (OLIVEIRA, 2012).

Não obstante, compreende-se que refletir numa perspectiva fenomenológica sobre a semiótica do lugar é também basilar para compreendermos as relações que nele se estabelecem. Nesta reflexão, Oliveira (2012) salienta que o lugar ainda se caracteriza por ser produto do meio físico, do meio social, da conceitualização (forma de ler, ver e estar no mundo), da figuração (representação/participação) dos sujeitos, do falar e do habitar. É a sociofísica do lugar, a qual precisa dos seis elementos em interação para dar corporeidade à vida humana e sua experiência no lugar, a partir do tempo. Mas como se estrutura isto? Segundo Oliveira (2012), de três maneiras: cruzando o habitar e o falar, em que o significado do lugar está na ênfase na linguagem e na forma de viver; cruzando o meio físico e o social (no mundo global atual é a forma mais vigente). Consiste em construir a identidade em um novo local. É radiante porque possibilita a construção o sentimento afetivo de pertencimento; e cruzando a conceitualização e a figuração: ambas são 
influenciadas pela forma de falar e de viver. A identidade se constitui dos valores e da linguagem dos sujeitos.

É oportuno salientar, ainda, que o sentido de lugar é subjetivo, e mesmo que, às vezes, pensa-se o lugar apenas como um meio físico, é inevitável a reflexão de que o sentido de lugar (significado) está interligado às experiências de vida dos sujeitos e que esse sentido pode se transformar durante a vida, de acordo com os acontecimentos que ocorrerem em certo lugar. Por isso, pode-se dizer que ele é um guardador de memórias. Dentre esses sentidos subjetivos, há de se lembrar que o lugar não está descontextualizado globalmente, pelo contrário, pois a razão global e a local convivem dialeticamente, embora por vezes negada, em pleno movimento e trocas de experiências. Neste aspecto, não há como negar a conjuntura crítica embutida no lugar e nem pensá-lo isoladamente. Sendo assim, é pertinente afirmar que o lugar está entre o tempo e o espaço. Visto que, de acordo com Oliveira (2012), o sentido de lugar implica o sentido da vida e, por sua vez, o sentido do tempo. Ou seja, o lugar é tempo lugarizado que se dá a partir da experiência vivida.

Isto acontece pelo fato do espaço geográfico ser uma construção sócio-histórica e, por isso, nele estar contido o lugar. Logo, noção de tempo, lugar e espaço estão associadas e são interdependentes, por (re)produzirem-se simultaneamente. Desse modo, o tempo lugarizado é o tempo significado pela experiência e existência humana no lugar, pelo estar-no-mundo heideggeriano; ou seja, o sentido do lugar se transforma com o passar do tempo e adquire outros significados, podendo se desenvolver criticamente, se estagnar e/ou alienar no processo de crescimento, ou desaparecer. Portanto, o espaço vivido não pode ser considerado neutro, mas, sim, marcado por transformações de percepções, sentidos e ações. Por isso, é um campo de disputa perene.

Todavia, por mais que o tempo global tente convencer os sujeitos sobre a liquidez do espaço, há lugares que resistem e se concretizam nisto. Neste caso, o sentido de pertencimento ao lugar é mais forte do que a ideologia sistemática global. É o exemplo claro de que são os sujeitos que pertencem aos lugares e não o contrário. Se assim fosse, o significado seria de posse, apregoado pela lógica capitalista dominante que aliena e segrega, e não de pertencimento que aposta na emancipação humana e na transformação social, a partir da participação. Neste sentido o pertencimento pode ser compreendido como

[...] uma crença ou ideia que une as pessoas, e é expresso por símbolos e valores sociais, morais, estéticos, políticos, culturais, religiosos e ambientais dentre outros de um lugar. Ele possibilita compreender como os processos das relações sociais estão presentes em cada vivência, e como o local e o global se traduzem em experiências pessoais e coletivas (COUSIN, 2010, p. 94-95). 
3 Esta artimanha é resultante da articulação entre as interações sociais e os acontecimentos do cotidiano e é influenciado pela semiótica do lugar. É subjetivo, pois os sentidos atribuídos e resultantes deste balé estão e são internalizados consciente e inconscientemente em cada sujeito, em um movimento contínuo de trocas.
A compreensão do pertencimento numa perspectiva crítica e emancipatória tem o lugar como locus onde se dão as vivências e, por consequência, as experiências humanas. Tal fato confirma a ideia de Carlos (2007) ao ajudar-nos a pensar sobre a importância do lugar para despertar o sentimento de pertencimento. Segundo ela:

O lugar é produto das relações humanas, entre homem e natureza, tecido por relações sociais que se realizam no plano do vivido, o que garante a construção de uma rede de significados e sentidos que são tecidos pela história e cultura civilizadora produzindo a identidade, posto que é aí que o homem se reconhece porque é o lugar da vida. O sujeito pertence ao lugar, pois a produção do lugar liga-se indissociavelmente a produção da vida. No lugar emerge a vida, pois é aí que se dá a unidade da vida social. Cada sujeito se situa num espaço concreto e real onde se reconhece ou se perde, usufrui e modifica, posto que o lugar tem usos e sentidos em si (CARLOS, 2007, p. 22).

Estas experiências sociais e coletivas que só são possíveis de ser estabelecidas a partir do ser-com (HEIDEGGER, 2015) são marcadas pelas circunstancialidades, que são cotidianas, momentâneas, relacionais e dinâmicas, e fazem com que os sujeitos atribuam significados subjetivos às coisas e ao mundo, que é um constructo social. As experiências fazem enxergar os entes de acordo com as vivências dos sujeitos e esse ser-no-mundo (HEIDEGGER, 2015) revela a mundanidade. É essa leitura de mundo que dá corporeidade à existência enquanto sujeitos. Assim, convém dizer que o ser se constitui no mundo e o mundo se constitui no ser (é produto e produz múltiplos significados). Seria isso o balé-dialético-do-lugar ${ }^{3}$ ? Para Seamon (2001 apud MELLO, 2012) a fusão entre o balé-do-corpo e as rotinas espaço-temporais forma o balé-do-lugar. Especialmente porque analisa a dinâmica das interações sociais e suas interações com o cotidiano vivido e partilhado.

Referente a isto, a esta dialética existencial, outros aspectos que merecem relevância são o ser e o espaço. Heidegger (2015) parte do princípio do ser em direção ao espaço. Giddens (2002) parte do espaço para pensar a constituição do ser. Pois bem, se uma análise minuciosa for realizada, percebe-se que esses pensamentos são simbióticos e indissociáveis. Não há como pensar ser e espaço separados. O ser é produto e produtor do espaço, assim como o lugar. Ele produz o espaço (a partir das horizontalidades que constitui o lugar, isto é, da experiência vivida), o espaço o produz cotidianamente (por meio das verticalidades que incidem sobre o lugar), logo o ser se autoproduz nas (inter) relações (ser-com) que acontecem nesses lugares delimitados por um período temporal. É o movimento que denominamos ser-espaço-ser. Na Figura 1, nota-se que este 
fenômeno não pode ser pensado em um movimento retilíneo mas, sim, cíclico.

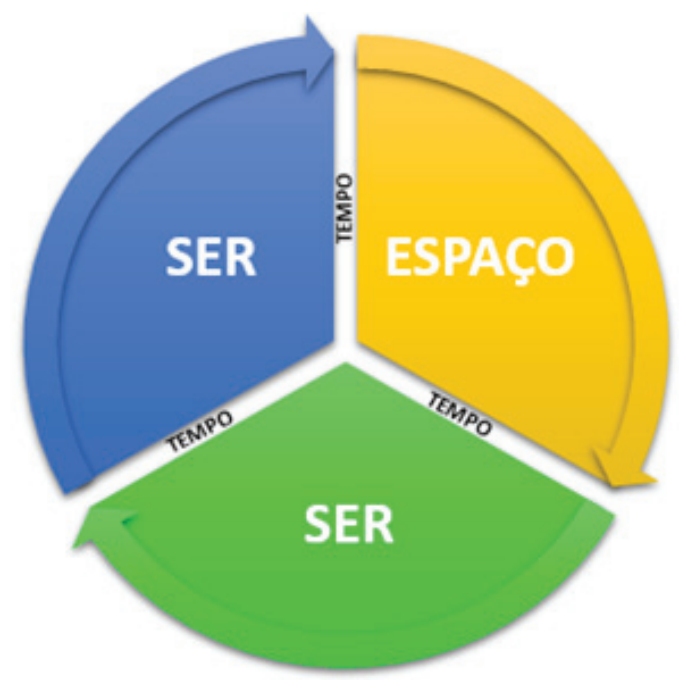

Figura 1 - Movimento Ser-Espaço-Ser Fonte: Elaborada pelos autores

É viável ressaltar que não é possível compreender esse fenômeno apenas com um elemento. É necessário vê-lo sistematicamente. É preciso compreender o mundo circundante de um lugar e/ou espaço para compreender sua interferência na construção do ser. Isto reforça a ideia de que ser-espaço-ser precisam ser vistos cíclica e sistematicamente, e não de modo fragmentado. Afinal, cada sujeito possui sentido no mundo e a constituição de cada um está entrelaçada aos mais diversos lugares por onde passa ao longo do tempo que demarca sua experiência mundana. Para compreender tal processo, Heidegger (2015) foi basilar a partir do ser-aí.

Este sentido no mundo que acontece por meio das relações dos sujeitos com os lugares e com as pessoas vem sofrendo uma fragilização, a partir da ciência moderna, como mencionado anteriormente. Cada vez mais os sujeitos são atingidos e envolvidos por turbilhões de informações do sistema, sem que, muitas vezes, percebam isto. Este excesso de estímulos corpóreos desordenados faz com que haja uma descorporificação (GRÜN, 2008) dos sujeitos em relação à conjuntura social vivida, fazendo com que a sensibilidade, a qual possibilitaria um estabelecimento de percepções primárias e profundas, se fragilize. Essa fragilidade de percepções faz com que a noção de lugar e a noção de estar em um lugar percam cada vez mais a intensidade de sentidos pelos sujeitos.

Nesse sentido, o geógrafo Milton Santos (2008) nos convida a refletir sobre o papel do meio-técnico-científico-informacional para a produção das identidades e sua infiltração nos lugares, produzindo a liquidez das relações, do espaço e do tempo. Segundo ele, os espaços assim requalificados atendem, sobretudo, aos interesses dos atores 
hegemônicos da economia, da cultura e da política e são incorporados plenamente às novas correntes mundiais. O meio técnico-científico-informacional é a cara geográfica da globalização e está a serviço dos vetores do capital. Destaca que o espaço geográfico é produzido pelo homem em diferentes temporalidades, ao relacionar-se com os outros, consigo mesmo e com a natureza, no lugar em que vive (SANTOS, 2008). Por isso, este autor nos ajudou a compreender que a relação experiência e lugar possuem um arcabouço existencialista-fenomênico que, na contemporaneidade, dialoga com a materialidade espacial, atribuindo a ela uma nova racionalidade.

Nesse viés, articulando com os pressupostos da EAE, Duarte Jr (2010), afirma que esta estimulação corpórea exagerada tem condicionado o olhar a uma percepção muito restrita, uma percepção fragmentada do mundo, onde a vida moderna tem privado os sujeitos dos sentidos que evocam memórias carregadas de significados e emoções: uma crise de sentidos chamada de anestesia, e que se manifesta nas relações entre os diferentes sujeitos e entre estes e o ambiente.

Esse balé-dialético-do-lugar que torna os sujeitos inertes precisa ser revertido, se há o desejo de fortalecer os lugares e os sentimentos de pertença a eles a partir da EA. Essa superação precisa partir de uma abertura para pensar uma nova forma de ser-e-estar no mundo, a partir de uma sensibilização socioambiental e, claro, existencial. Se os sujeitos são aquilo que escolhem e se conhecem a partir do lugar que estão, as atitudes e escolhas precisam ser coerentes com aquilo que pensam, com suas memórias sensoriais, com sua existência corpórea e que os constitui como ser-sujeito histórico, sem cair nas armadilhas das topofilias e/ou topofobias (TUAN, 2012).

O pertencimento relaciona-se com a nossa identidade, pelo conjunto de significados e sensações que o lugar imprime em nós, enquanto sujeitos históricos e, ao mesmo tempo, desperta nosso senso de responsabilidade mediado pela práxis. Está diretamente relacionado com a noção de participação. Com o engajamento mútuo dos atores sociais e com o (com)partihar de repertórios, os elementos construídos de forma participativa desenvolvem a co-responsabilidade, e esse processo pertence à coletividade e tornar-se um devir para a transformação social. (COUSIN, 2010).

Trazer essa discussão da EAE e da importância de compreender o papel do pertencimento ao lugar para pensar a integração da EA nos cursos superiores pode ser uma contribuição importante para a AC. Isto porque para que seja possível ambientalizar os currículos é necessário haver conhecimento do campo da EA, do lugar (IES e as dimensões do próprio mercado de trabalho futuro) e da área de atuação profissional. Neste âmbito, a estética e o pertencimento podem ser basilares para esse processo se potencializar. 


\section{O SENTIDO DE PERTENCIMENTO E A EDUCAÇÃO AMBIENTAL ESTÉTICA NO PROCESSO DE AMBIENTALIZAÇÃO CURRICULAR NA EDUCAÇÃO SUPERIOR}

Nesta seção serão abordadas as discussões acerca dos conceitos e características do processo de AC nas Educação Superior e as articulações necessárias do sentido de pertencimento ao lugar e da EAE na potencialização deste processo.

O processo de $\mathrm{AC}$ vem sendo discutido por diferentes autores e autoras, tanto na educação básica (SANMARTI; PUJOL, 2002; COPELLO LEVY, 2004; 2006), quanto no ensino superior (MOTA; KITZMANN, 2017; KITZMANN; MOTA, 2017; GUERRA e FIGUEIREDO, 2015; KITZMANN e ASMUS, 2012; MARCOMIN e SILVA, 2010, OLIVEIRA, 2006, dentre outros). Ela pode ser conceituada, de acordo com a Rede de Ambientalização Curricular no Ensino Superior - Rede ACES (2002), como um processo contínuo de produção cultural de outras possíveis relações entre a sociedade e a natureza, com justiça socioambiental, solidariedade, equidade e ética universal e deferência às diversidades. Ainda, para Guerra e Figueiredo (2014, p. 111), "A ambientalização curricular compreende a inserção de conhecimentos, de critérios e de valores sociais, éticos, estéticos e ambientais nos estudos e currículos universitários, no sentido de educar para a sustentabilidade socioambiental."

Assim, percebe-se que o processo de ambientalização nas IES atinge sua organização, seu funcionamento, suas ações e os sujeitos que ali estão inseridos. Tanto o currículo explícito como o oculto são afetados, surgindo outras maneiras de pensar e formas de trabalho que quebram paradigmas de ensino tradicionais (SANMARTÍ; PUJOL, 2002). Este processo precisa proporcionar, a priori, bases epistemológicas que servirão de suporte nas práticas dos sujeitos enquanto cidadãos e também profissionais. Isso corrobora as ideias de Kitzmann e Asmus (2012), quando afirmam que o processo de ambientalização também está baseado na ressignificação de valores e práticas, com o objetivo de integrar conceitos e referenciais da EA, seja nos currículos que já estão construídos ou em modelos curriculares que estejam sendo ou virão a ser elaborados.

Nesse sentido, as IES se apresentam como um importante centro para a formação em EA, sensibilização, e à ressignificação de valores, percepções e conceitos, principalmente na organização e na valorização dos saberes com o intuito de aproximar-se das situações socioambientais da sociedade. Para isto, é necessário que o currículo tradicional que ainda predomina nesses ambientes de aprendizagem se transforme em um currículo ambientalizado, buscando subsídios norteadores em uma EAE que também é transformadora e emancipatória. Dessa forma, poderá contribuir para o desenvolvimento humano de forma sis- 
têmica que discuta e reflita sobre as questões socioambientais diante do cenário de degradação da vida planetária.

No que se refere ao sentimento de pertença, este se mostra como uma importante ferramenta no processo de AC. O pertencimento ao lugar é uma condição sine qua non quando se refere à integração dos valores socioambientais, dos princípios da EA e dos valores sociais, éticos, estéticos, em um determinado ambiente. Para pensar na implantação de um processo tão complexo como o da AC é importante compreender que a ambientalização é um empreendimento conjunto, pois exige o compartilhamento de repertórios e requer engajamento coletivo no seu planejamento. Este ser-com precisa ter e ser sentido em relação ao lugar e aos demais sujeitos que ali produzem e (re)transformam suas formas de ser-e-estar no mundo (HEIDEGGER, 2015).

Considerando isto, percebe-se que o sentido de pertencimento pode influenciar e ser influenciado pela ambientalização curricular, haja vista que para que possa haver uma sensibilização, um ato reflexivo e um agir diante a uma situação de desencaixe social, este processo "Não pode estar baseado em ações isoladas e pontuais, sejam teóricas ou práticas, mas num compromisso institucional, o que demandará mudanças administrativas e estruturais, para que seja efetivamente implementado" (KITZMANN, 2007, p. 554). Afinal, como afirma Goergen (2000, p. 158), as IES precisam "[...] quebrar o grilhão do individualismo, do isolamento, do corporativismo e do egoísmo, para gerar uma solidariedade fecunda, como sementeira de uma forma de ser, de agir e de saber". Ou seja, requer despertar um sentimento de pertencimento ao lugar (IES enquanto espaço formador), ao campo de atuação profissional e ao campo da educação ambiental, conforme proposto por Cousin (2010) ao discutir elementos basilares para pensar o processo de formação e constituição de educadores ambientais.

A partir da implementação de um trabalho coletivo, os lugares poderão ser (re)significados na memória de cada sujeito, despertando o sentimento de pertencimento a um lugar que é coletivo, é plural, é diverso, é dinâmico e é participativo, sendo também subjetivo. Dessa forma, o lugar reflete uma organização social em sua dinâmica, em sua simbiose, em sua potência, deixando visíveis suas fragilidades e limites. Pois é constituído e constitutivo dos seres humanos em sua plenitude.

E como fazer para transformar essas fragilidades e limites dos lugares em potências no processo de AC? E, ainda, como indaga Grün (2008): Como a EA pode contribuir para a (re)apropriação social desses lugares? Uma das possibilidades é a valorização da experiência humana nesse processo, não somente no sentido laboral, mas também de sentimentos, em uma dialética constante. Para isto, buscam-se os legados da fenomenologia da percepção (MERLEAU-PONTY, 2006), com vistas a um resgate de um corpo-vivido-sensível capaz de (re)construir 
práticas ecologicamente corretas de viver em um lugar, neste caso, nas IES. Esse corpo permitiria o (re)encontro de um caminho para o sentido de lugar, criando vínculos de pertencimento.

Indissociável a isto, há uma urgente necessidade de um fortalecimento da EAE que resgate o elo entre o homem, a natureza e os lugares, que possibilite (re)determinar valores, (re)pensar atitudes, buscando a existência do (com)partilhar, necessário para (re)transformar a atual conjuntura social a que os sujeitos estão integrados. Essa EAE permite

[...] que os valores culturais e subjetivos de cada indivíduo passam a ser respeitados e trabalhados, que os sujeitos conseguem internalizar e perceber o seu lugar no mundo, percebendo que o meio ambiente não é um espaço em que simplesmente estão inseridos, mas sim, que cada qual é um ser que o constitui, interage, e é constituído nas relações que se estabelecem nesse meio. Quando essa internalização acontecer, as questões ambientais passarão a ter razões e significados, e não passarão despercebidas dentro, e além dos muros que ainda cercam as instituições, separando-as da comunidade de vida do planeta (MOTA, 2015, p. 45-46).

Ora, este pensamento vem ao encontro da relevância do processo de AC. Qual o sentido de ambientalizar os currículos das IES se os sujeitos que pertencem àquele lugar de formação, seja ela inicial ou continuada, não se sentem integrados? E, além disto, qual a justificativa de ter currículos ambientalizados sem que os sujeitos compreendam a importância da EA na vida individual (enquanto cidadãos e profissionais em formação que atuarão para além dos muros das IES) e coletiva? Sem essa compreensão de sentidos, a ambientalização passa a ser mais um discurso em meio a tantos outros que emergem no âmbito acadêmico-social que não se converte em práticas ambientais e com sustentabilidade, por falta de uma sensibilização, compreensão, responsabilidade e cidadania ambiental dos que ali vivenciam e produzem suas experiências de vida.

\section{CONSIDERAÇÕES ATUAIS}

A AC vem sendo alvo das discussões no que se diz respeito a integração de dimensões socioambientais e sustentáveis nos currículos, sejam eles no ensino superior ou na educação básica. Entretanto, é necessário mencionar que a ambientalização não se propõe somente a integrar dimensões socioambientais e/ou ecológicas nos currículos, transformando-os, muitas vezes, em currículos verdes sem intenções práticas, mas também requer a integração de valores, dimensões estéticas, éticas e de responsabilidade 
individual, coletiva e para com o meio ambiente visto como um campo de múltiplas inter-relações.

Para que isto ultrapasse a utopia e trilhe para uma realidade vivida, uma das situações que precisam ser consideradas é o sentimento de pertencimento ao lugar que indivíduos e coletividades experimentarão e potencializarão a AC. Como já visto, este processo requer a participação de todos os sujeitos que ali constroem suas experiências de vida, e se estes não se sentirem pertencentes ao lugar, a ambientalização se torna uma espécie de quebra-cabeças com peças faltantes, não sendo possível exercer uma ação sistêmica mas, sim, fragmentada e muitas vezes sem significados para a comunidade universitária e local.

Perante isto, a educação ambiental estética emerge como uma possível ferramenta na (re)apropriação dos sentidos dos lugares nesta modernidade cada vez mais líquida. As percepções profundas precisam ser (re)estabelecidas, afim de que não haja a banalização dos acontecimentos mas, sim, sejam vistos com outras lentes que visem uma transformação social e humana. É importante também que a essência e as experiências produzidas nas circunstancialidades da mundanidade não sejam diluídas nessa liquidez do espaço e do tempo mas, sim, que se fortaleçam e resistam às imposições do atual sistema que insiste em absorver tudo e todos. Ou seja, a proposta é a construção de uma outra forma de ser-e-estar no mundo (HEIDEGGER, 2015) que seja mais justa, menos desigual, com sustentabilidade ambiental, solidariedade e participação.

\section{REFERÊNCIAS}

BAUMAN, Zygmunt. Modernidade líquida. Rio de Janeiro: Zahar, 2003.

BRASIL. Ministério da Educação. Lei no 9.795, de 27 de abril de 1999. Dispõe sobre a educação ambiental, institui a Política Nacional de Educação Ambiental - PNEA e dá outras providências. Diário Oficial da República Federativa do Brasil. Brasília, DF: Brasília, 1999.

CARLOS, Ana Fani Alessandri. O lugar no/do mundo. São Paulo: Labur Edições, 2007.

COPELLO LEVY, Maria Inés. Escola ambientalizada e formação de professor@s: compromissos e desafios. In: TAGLIEBER, José Erno; GUERRA, Antonio Fernando Silveira. Pesquisa em educação ambiental: pensamentos e reflexões. Pelotas, UFPel, 2004, p. 105-143.

COPELLO LEVY, Maria Inés. Fundamentos teóricos e metodológicos de pesquisas sobre ambientalização da escola. Pesquisa em Educação Ambiental. v. 1, n. 1, p. 93-110, jul. /dez, 2006. 
COUSIN, Claudia da Silva. Pertencer ao navegar, agir e narrar: a formação de educadores ambientais. 2010. 207 f. Tese (Doutorado) - Doutorado em Educação Ambiental, FURG, Rio Grande, 2010.

DUARTE JR, João Francisco. O sentido dos sentidos. 5 . ed. Curitiba: Criar, 2010.

FIGUEIREDO, Mara Lúcia et al. Ambientalização nas Instituições de Educação Superior: reflexões do IV Seminário Sustentabilidade na Universidade. In: RUSCHEINSKY, Aloísio et al. Ambientalização nas Instituições de Educação Superior no Brasil: caminhos trilhados, desafios e possibilidades. São Carlos: EESC/USP, 2014. p. 337-349.

GIDDENS, Anthony. Modernidade e identidade. Rio de Janeiro: J. Zahar, 2002.

GOERGEN, Pedro. A crise de identidade da universidade moderna. In: SANTOS FILHO, José Camilo; MORAES, Silvia. (Orgs.). Escola e universidade na pós-modernidade. Campinas: Mercado de Letras, 2000.

GRÜN, Mauro. A importância dos lugares na Educação Ambiental. In: Rev. eletrônica Mestr. Educ. Ambient. v. especial, dezembro de 2008. Disponível em: <https:// www.seer.furg.br/remea/article/view/3384>. Acesso em: O5 set. 2017.

GUERRA, Antonio Fernando Silveira. Ambientalização e sustentabilidade nas universidades: subsídios, reflexões e aprendizagens. Ebook. Ed. da Univali, Itajaí, 2015.

GUERRA, Antonio Fernando Silveira; FIGUEIREDO, Mara Lucia. Ambientalização curricular na Educação Superior: desafios e perspectivas. Educar em Revista, Curitiba, Brasil, Edição Especial n. 3/2014, p. 109-126. Editora UFPR.

GUERRA, Antonio Fernando Silveira et al. Ambiente e sustentabilidade no sistema nacional de ciência, tecnologia e inovação do Brasil. Ambiens. Revista Iberoamericana Universitária en Ambiente, Sociedade y Sustentabilidade. 2015, n. 1, p. 125-138. Disponível em: <http://ppct.caicyt.gov.ar/index.php/ambiens/article/ view/3227>. Acesso em: 20 jun. 2017.

GUIMARÃES, Mauro et al. Educadores ambientais nas escolas: as redes como estratégias. Cadernos CEDES (Impresso), v. 29, p. 49, 2009.

HEIDEGGER, Martin. Ser e tempo. 10. ed. Petrópolis: Vozes, 2015. 
KITZMANN, Dione. Ambientalização de espaços educativos: aproximações conceituais e metodológicas. Rev. eletrônica Mestr. Educ. Ambient, v. 18, janeiro a junho de 2007, 553 - 574. Disponível em: <https://www.seer.furg. br/remea/article/view/3588> . Acesso em: 15 ago. 2017.

KITZMANN, Dione; ASMUS, Milton. Ambientalização sistêmica: do currículo ao socioambiente. Currículo Sem Fronteiras, v. 12, n. 1, p. 269-290, jan./abr. 2012.

KITZMANN, Dione Iara Silveira; MOTA, Junior Cesar. Ambientalização sistêmica nas instituições de ensino superior. In: FIGUEIREDO, Mara Lúcia; et al. (Orgs.). Educação para ambientalização curricular: diálogos necessários. São José: ICEP, 2017, p.181-194.

MARCOMIN, Fatima Elizabeti; SILVA, Alberto Dias Vieira. A sustentável leveza da universidade. In: GUERRA, Antonio Fernando Silveira; FIGUEIREDO, Mara Lucia. Sustentabilidades em diálogos. Itajaí: Univali, 2010. p. 171-189.

MARIN, Andreia Aparecida; OLIVEIRA, Claudio Batista de. A experiência estética em Dufrenne e Quintás e a percepção de natureza: para uma educação ambiental com bases fenomenológicas. Revista Eletrônica do Mestrado em Educação Ambiental. Rio Grande, RS: v.15, p.196210, jul./dez. 2005. Disponível em: <https://www.seer. furg.br/remea/article/view/2935/1660 >. Acesso em: 10 jul. 2017.

MELO FILHO, Benício de. Turismo e sustentabilidade: estudo do Vivat Floresta Park em Tijucas do Sul, PR. 2006. 181 f. Tese. (Doutorado em Engenharia Florestal) Universidade Federal do Paraná - UFPR, Curitiba, 2006. Disponível em: <http://www.floresta.ufpr.br/defesas/ pdf_dr/2006/t201_0230-D.pdf>. Acesso em 05 ago. 2017.

MERLEAU-PONTY, Maurice. Fenomenologia da percepção. 3. ed. São Paulo: Martins Fontes, 2006.

MORALES, Angélica Gois. A formação dos profissionais educadores ambientais e a universidade: trajetórias dos cursos de especialização no contexto brasileiro. Educar em Revista (Impresso), v. 34, p. 185-199, 2009.

MOREIRA, Ruy. Para onde vai o pensamento geográfico?: por uma epistemologia crítica. São Paulo: Contexto, 2006.

MOTA, Junior Cesar. A Educação Ambiental Estética como uma ferramenta à (re)significação do ser-sensível. In: IV Seminário Interfaces Pedagógicas: Licenciaturas em diálogo, 2016, Rio Grande. Anais.... Rio Grande: Pluscom, 2016. v. 4. p. 38-41. Disponível em: <http://media.wix.com/ugd/ 
c76807_e4d91a75df3a44b39bo8233550658a4d.pdf $>$. Acesso em: 27 set. 2017.

MOTA, Junior Cesar. Limites e possibilidades na transição para espaços educadores sustentáveis em escolas municipais de São João Batista - SC. 127 f. Dissertação. (Mestrado em Educação) - Universidade do Vale do Itajaí, Itajaí, 2015.

MOTA, Junior Cesar; KITZMANN, Dione Iara Silveira. Um Estado da Questão sobre Ambientalização Curricular na Educação Superior brasileira: práticas, desafios e potencialidades. REMEA - Revista Eletrônica do Mestrado em Educação Ambiental, v. 34, n. 3, p. 72-92, dez. 2017. Disponível em: <https://periodicos.furg.br/remea/ article/view/7475/4884>. Acesso em: 29 mar. 2018.

OLIVEIRA, Haydée Torres de. O processo de ambientalização curricular na Universidade Federal de São Carlos nos contextos de ensino, pesquisa, extensão e gestão ambiental. In: CONGRESSO IBERO-AMERICANO DE EDUCAÇÃO AMBIENTAL. 5, Anais... Joinville-SC, abril 2006. p. $453-458$.

OLIVEIRA, Lívia de. O sentido de lugar. In: MARANDOLA JR, Eduardo et al. Qual o espaço do lugar?: geografia, epistemologia, fenomenologia. São Paulo: Perspectiva, 2012.

REDE ACES. Ambientalización curricular de los estudios superiores 2 - Proceso de Caracterización de la Ambientalización Curricular de los Estudios Superiores. Girona: Universitat De Girona - Red Aces, 2002.

SANMARTÍ, Neus; PUJOL, Rosa María. ¿Qué comporta capacitar para la acción? Sevilla, Investigación en la Escuela. n. 46, p. 49 - 54, 2002. Disponível em: <http:// www7.uc.cl/sw_educ/educacion/grecia/plano/html/ pdfs/linea_investigacion/Educacion_Ambiental_IEA/ IEA_005.pdf >. Acesso em: 14 ago. 2016.

SANTOS, Boaventura de Sousa. Um discurso sobre as ciências. 4. ed. São Paulo: Cortez, 2006.

SANTOS, Milton. A natureza do espaço. Técnica e Tempo. Razão e Emoção. 4. ed. São Paulo: Universidade Federal de São Paulo, 2008.

SATO, Michèle; SANTOS, José Eduardo. Tendências nas pesquisas em educação ambiental. In: NOAL, Fernando; BARCELOS, Valdo. (Orgs). Educação ambiental e cidadania: cenários brasileiros. Santa Cruz do Sul: EDUNISC, 2003. p. 253-283.

SAUVÉ, Lucie. Educação Ambiental: possibilidades e limitações. Educação e Pesquisa, São Paulo, v. 31, n. 2, 
p.317-322, ago. 2005. Disponível em: <www.revistas.usp. br/ep/article/view/27979>. Acesso em: o5 jun. 2017.

TAVARES, Claudia Moraes Silveira et al. Estética e Educação Ambiental no paradigma da complexidade. Pesquisa em Educação Ambiental. V. 4., n.1, p. 177-193, 2009. Disponível em: <http://www.revistas.usp.br/pea/article/ viewFile/30081/31968>. Acesso em: 12 set. 2017.

TOZONI-REIS, Marilia Freitas de Campos. Temas ambientais como "temas geradores": contribuições para uma metodologia educativa ambiental crítica, transformadora e emancipatória. Educ. rev., Curitiba, n. 27, p. 93-110, jun. 2006. Disponível em: <http://dx.doi.org/10.1590/So10440602006000100007>. Acesso em: 01 jun. 2017.

TUAN, YI-Fu. Topofilia: um estudo da percepção, atitudes e valores do meio ambiente. Londrina: Edcel, 2012.

WARSCHAUER, Cecília. Rodas em rede: oportunidades formativas na escola e fora dela. Rio de Janeiro: Paz e Terra, 2001.

Recebido em: 27/09/2017 Aprovado em: 14/12/2017 Publicado em: 31/12/2018 